\title{
The Rivaroxaban Program and the Management of Unmet Needs in Thromboembolic Disease
}

\author{
A. John Camm ${ }^{1}$ \\ ${ }^{1}$ Division of Clinical Sciences, St George's, University of London and \\ Imperial College, Cranmer Terrace, London, United Kingdom \\ Thromb Haemost 2018;118 (Suppl 1):S2-S11.
}

\begin{abstract}
Address for correspondence A. John Camm, MD, Cardiovascular Sciences Research Centre, Division of Clinical Sciences, St George's, University of London, London SW17 ORE, United Kingdom (e-mail: jcamm@sgul.ac.uk).
\end{abstract}

Abstract


Keywords
- atherothrombosis
- coronary artery
disease
- stroke
- rivaroxaban

Rivaroxaban is a non-vitamin $\mathrm{K}$ antagonist oral anticoagulant that acts as a direct factor Xa inhibitor, and is widely used for the prevention and treatment of thromboembolic disorders. As further knowledge gaps are identified in thrombosis management, the rivaroxaban research program has expanded in an attempt to elucidate the wider benefits of rivaroxaban. An increased understanding of the interactions taking place within the coagulation cascade may support a broader role for rivaroxaban $(2.5 \mathrm{mg}$ twice daily [bid] or $5 \mathrm{mg}$ bid) in the setting of vascular protection, either alone or in combination with an antiplatelet agent. The aim of this article is to describe the potential role of rivaroxaban in the context of vascular protection and provide an overview of recently completed and ongoing randomized controlled trials of rivaroxaban in the areas of stroke prevention, venous protection and vascular protection.

\section{The Rivaroxaban Clinical Research Program}

Rivaroxaban is a non-vitamin $\mathrm{K}$ antagonist (VKA) oral anticoagulant (NOAC), which acts as a direct factor Xa inhibitor. ${ }^{1}$ The first marketing authorization for rivaroxaban in the European Union (EU) was for the prevention of venous thromboembolism (VTE) in adult patients undergoing elective knee or hip replacement surgery. ${ }^{2}$ Since 2008 , there has been an extensive program of randomized controlled trials (RCTs) to evaluate the safety and efficacy of rivaroxaban in an increasing range of patient populations.

Rivaroxaban is approved for a total of seven indications, across five clinical areas of use: ${ }^{2}$

1. The prevention of VTE in adult patients undergoing elective hip replacement surgery. ${ }^{3,4}$

2. The prevention of VTE in adult patients undergoing elective knee replacement surgery. ${ }^{5,6}$

3. The prevention of stroke and systemic embolism in adult patients with nonvalvular atrial fibrillation (NVAF). ${ }^{7}$

4. Treatment of deep vein thrombosis (DVT) in adults. ${ }^{8}$
5. Treatment of pulmonary embolism (PE) in adults. ${ }^{9}$

6. Prevention of recurrent DVT and PE in adults. ${ }^{8,9}$

7. The prevention of atherothrombotic events in adult patients following acute coronary syndrome (ACS) with elevated cardiac biomarkers, co-administered with acetylsalicylic acid (ASA) alone or with ASA plus clopidogrel or ticlopidine. ${ }^{10}$

More than 275,000 patients will have been included in clinical trials or registries by the close of the clinical development program for rivaroxaban. ${ }^{11}$

The rivaroxaban research program includes RCTs (both company-sponsored and investigator-initiated research) with real-world evidence disseminated from non-interventional studies, patient registries and clinical database studies. One notable area of research is in the setting of vascular protection, where investigations are ongoing into the most optimal antithrombotic therapies for reducing long-term residual cardiovascular $(\mathrm{CV})$ risk, while minimizing bleeding risk. ${ }^{12,13}$ The aim of this article is to present an overview of the current understanding of the mechanisms of action of received

September 29, 2017

accepted after revision

December 23, 2017
Copyright @ 2018 Schattauer

DOI https://doi.org/

10.1055/s-0038-1632387. ISSN 0340-6245. 
rivaroxaban and to provide an overview of RCTs of rivaroxaban in stroke prevention, venous protection and vascular protection (-Fig. 1 ).

\section{The Coagulation Cascade and Potentiation of Antithrombotic Efficiency with Rivaroxaban}

Coagulation involves a complex interaction between platelets, the endothelium, endogenous procoagulant and anticoagulant proteins, and fibrinolytic factors, to prevent excessive propagation of thrombus and respond to acute vascular damage. ${ }^{14}$

Factor Xa has a central role in coagulation, as it results from the activation of factor $X$ by either the intrinsic or extrinsic coagulation pathway. ${ }^{1,14}$ During the initiation phase of coagulation, the factor Xa produced generates some thrombin (factor IIa). This initial thrombin activates factor XI, and factors V and VIII, to factor XIa and the activated cofactors, factor Va and VIIIa, respectively. Thrombin also activates platelets, which are required for the formation of the intrinsic tenase (factor VIIIa-factor IXa) and the prothrombinase (factor Va-factor Xa) complexes. The prothrombinase complex, on the platelet surface, is substantially more efficient than free factor Xa (in plasma) at activating prothrombin to thrombin; the rate of thrombin formation is increased by approximately 300,000-fold over the rate with factor Xa alone. ${ }^{1}$ Owing to its multiple roles in the coagulation process, thrombin is the principal enzyme involved in the formation, growth and stabilization of thrombi. ${ }^{1,15}$

Reducing thrombin generation by inhibition of factor Xa, together with a reduction in platelet aggregation using antiplatelet agents, may potentiate the efficacy of antithrombotic treatment, as previously shown in preclinical studies of rivaroxaban. ${ }^{16}$ While anticoagulants and antiplatelets both contribute to this effect, thrombin is a key target owing to its multifaceted role in platelet activation, fibrin formation and protein $\mathrm{C}$ activation-a concept that has been gaining ground in recent years, with hypotheses that inhibition of thrombininduced platelet activation might provide a larger therapeutic index. $^{12}$ The clinical benefits of two rivaroxaban doses (2.5 mg twice daily [bid] and $5 \mathrm{mg}$ bid) were shown in the ATLAS ACS 2-TIMI 51 (Anti-Xa Therapy to Lower Cardiovascular Events in Addition to Standard Therapy in Subjects With Acute Coronary Syndrome ACS 2-Thrombolysis In Myocardial Infarction 51) trial, where both doses significantly reduced the composite endpoint of death from CV causes, myocardial infarction (MI) or stroke, when used on background therapy (ASA/clopidogrel) in patients with ACS, including those presenting with heart failure (HF). ${ }^{10,17}$ These findings support the rationale for ongoing RCTs investigating rivaroxaban (2.5 and $5 \mathrm{mg}$ bid) as part of antithrombotic regimen for long-term CV protection. Two distinct approaches with rivaroxaban have been developed, which differ depending on the location of the clot and the nature of the thromboembolic event: anticoagulation for thromboembolic events or antithrombotic therapy for vascular events, comprising rivaroxaban $2.5 \mathrm{mg}$ bid and an antiplatelet, or rivaroxaban $5 \mathrm{mg}$ bid alone (-Fig. 2).

\section{Vascular Protection with Rivaroxaban: An Update on Ongoing Trials}

RCTs in the rivaroxaban vascular protection program include patients with acute and chronic coronary artery disease (CAD) and/or peripheral arterial disease (PAD). The trials are based on the hypotheses that targeted inhibition of thrombin generation with rivaroxaban with or without an antiplatelet in these patients may stabilize multiple pathophysiological processes and help reduce morbidity and mortality.

The prevention and treatment of atherothrombosis in acute and chronic CAD requires clinical attention owing to a continued residual risk of atherothrombotic events with antiplatelet therapy, ${ }^{18}$ which is also the case for those with PAD. ${ }^{19,20}$ CAD may also commonly occur in those with PAD, and patients with both CAD and PAD may be at increased risk of MI, stroke or death due to CV events, or all-cause mortality. ${ }^{20,21}$ Moreover, patients with PAD and/or CAD may present with more extensive and calcified coronary atherosclerosis, constrictive vascular remodelling and accelerated disease progression. ${ }^{22}$

The phase III ATLAS ACS 2-TIMI 51 and oPen-label, randomized, controlled, multicentre study explorIng twO treatmeNt stratEgiEs of Rivaroxaban and a dose-adjusted oral vitamin $\mathrm{K}$ antagonist treatment strategy in patients with Atrial Fibrillation who undergo Percutaneous Coronary Intervention (PIONEER AF-PCI) trials of rivaroxaban provide further support for the potential benefit of this agent in CAD and, by extension, in PAD. ${ }^{10,23}$ In PIONEER AF-PCI, data from patients with an indication for long-term anticoagulation undergoing $\mathrm{PCI}$ showed that using rivaroxaban plus a single antiplatelet agent, rather than rivaroxaban plus dual antiplatelet therapy (DAPT), reduced bleeding risk without increasing the risk of ischemic events. ${ }^{23}$

Coronary artery atherothrombosis, resulting in myocardial ischemia is the most common underlying cause of HF. ${ }^{24}$ The pathogenesis of increased thrombosis in patients with HF may be due in part to hypercoagulability ${ }^{25-27}$ and, therefore, anticoagulants may be important in the prevention of CV events in HF for patients with sinus rhythm. ${ }^{28}$ In addition, there are a lack of conclusive data supporting a definitive role of anticoagulants in patients with $\mathrm{HF}^{29-31}$

In each of these patient groups, it is clear that further research is essential to ascertain the most appropriate management strategies and minimize thrombotic risk. In the rivaroxaban vascular protection program, the following key trials are ongoing or have recently completed.

\section{Cardiovascular OutcoMes for People using Anticoagulation StrategieS: COMPASS}

COMPASS is a landmark phase III trial designed to determine the efficacy and safety of rivaroxaban, rivaroxaban plus ASA, or ASA alone for reducing the risk of MI, stroke and CV death in patients with stable atherosclerotic disease. ${ }^{32-34}$ COMPASS included 27,395 patients with CAD or PAD receiving a $1: 1: 1$ ratio of rivaroxaban $2.5 \mathrm{mg}$ bid + ASA $100 \mathrm{mg}$ once daily (od); rivaroxaban $5 \mathrm{mg}$ bid; or ASA $100 \mathrm{mg}$ od. Another randomized comparison is still ongoing and is comparing 
A Stroke Prevention
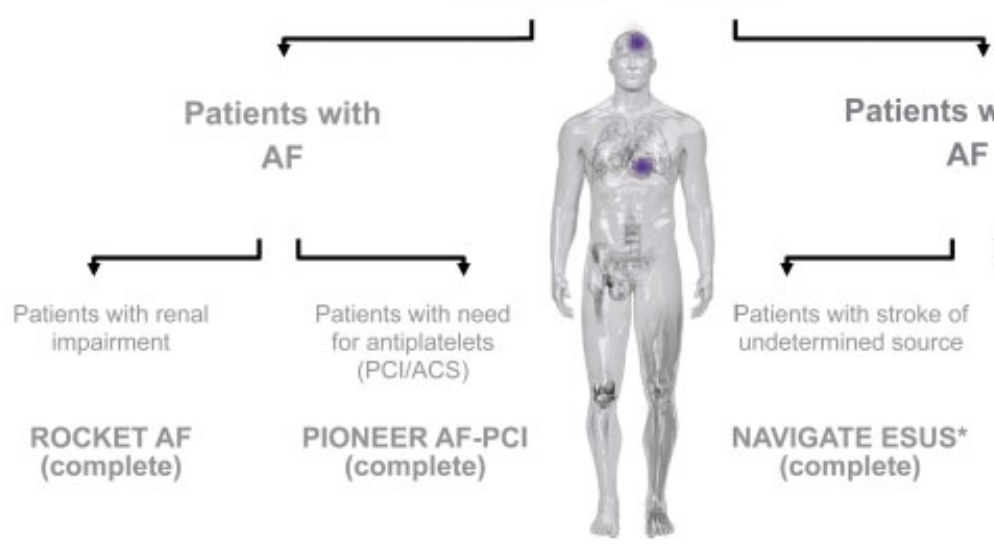

(complete)

B

\section{Venous Protection}

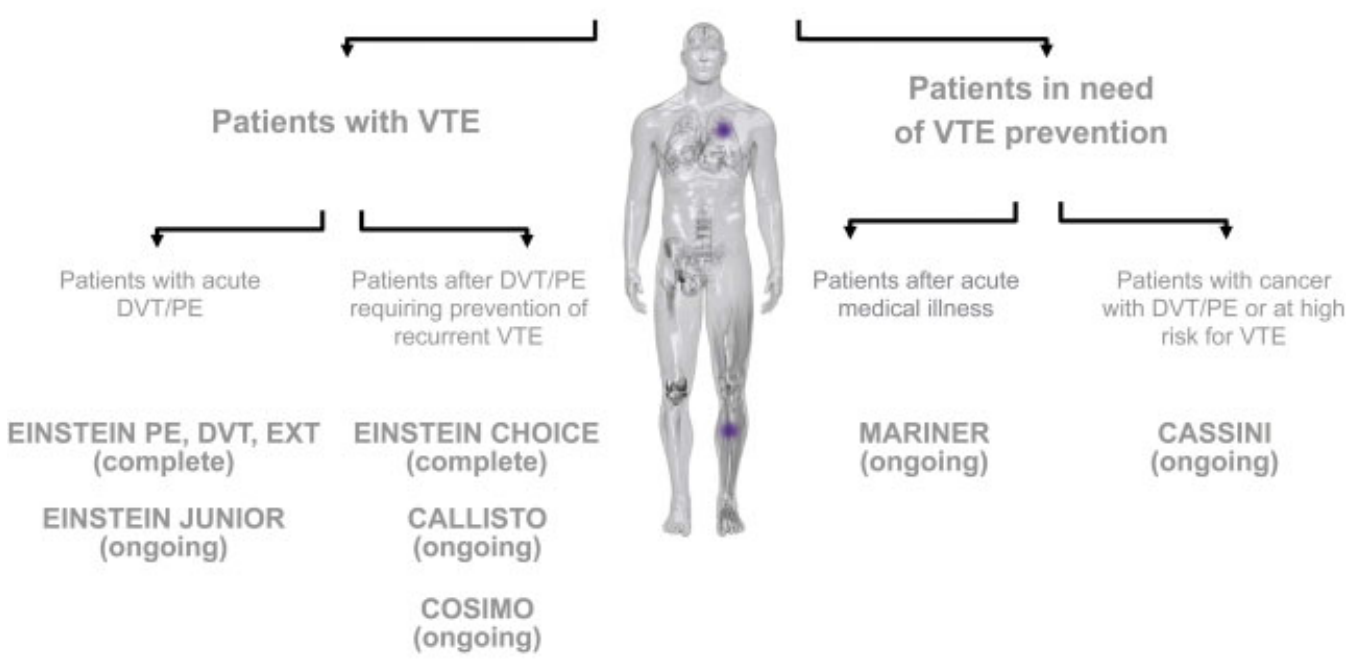

C

Vascular Protection

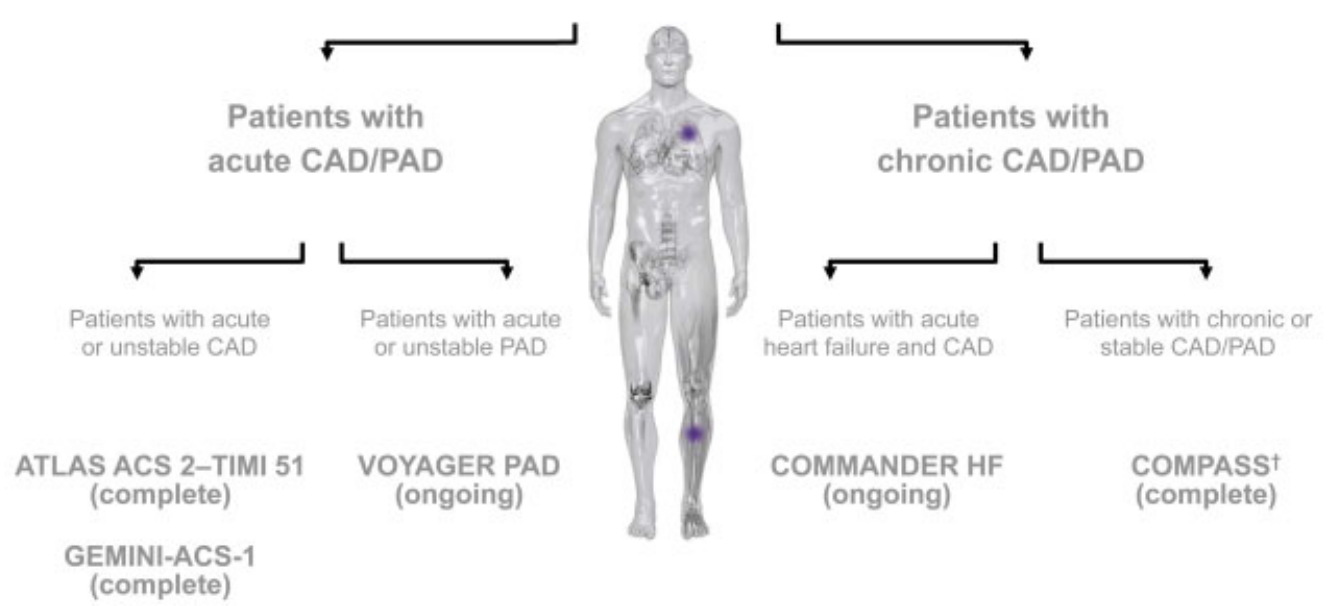

Fig. 1 Areas of focus in the rivaroxaban program: (A) stroke prevention, (B) venous protection and (C) vascular protection. *Data not yet available. Criteria for ESUS contrast with the original definition proposed by the Cryptogenic Stroke/ESUS International Working Group in three main ways: intracranial arterial imaging is not required, intracranial arterial occlusion does not exclude participation if diagnosed as embolic, and exclusion based on echocardiography is limited to intracardiac thrombus ${ }^{59}$. ${ }^{\dagger}$ Pantoprazole arm still ongoing. Abbreviations: ACS, acute coronary syndrome; AF, atrial fibrillation; CAD, coronary artery disease; DVT, deep vein thrombosis; ESUS, embolic stroke of undetermined source; PAD, peripheral arterial disease; $\mathrm{PCl}$, percutaneous coronary intervention; PE, pulmonary embolism; VTE, venous thromboembolism. 


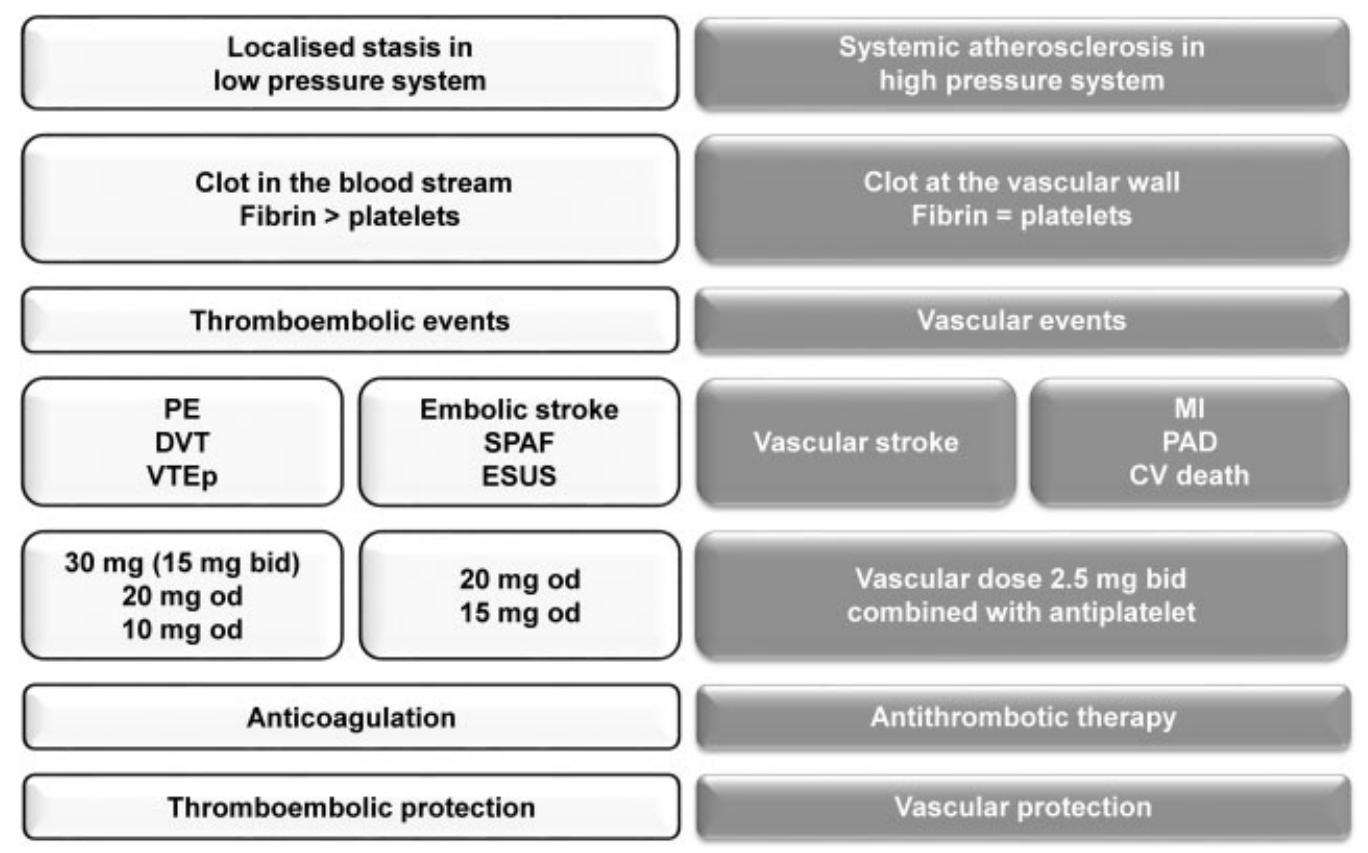

Fig. 2 An overview of anticoagulation strategies with rivaroxaban across a spectrum of thromboembolic and atherothrombotic disorders. Abbreviations: Bid, twice daily; CV, cardiovascular; DVT, deep vein thrombosis; ESUS, embolic stroke of undetermined source; MI, myocardial infarction; od, once daily; PAD, peripheral arterial disease; PE, pulmonary embolism; SPAF, stroke prevention in atrial fibrillation; VTEp, venous thromboembolism prevention.

pantoprazole with placebo in those patients not receiving a proton-pump inhibitor (the main outcome is upper gastrointestinal complications).

The primary efficacy endpoint of the trial was the composite of MI, stroke or CV death. ${ }^{34}$ The primary safety outcome was based on a modification of the International Society on Thrombosis and Haemostasis (ISTH) criteria and included fatal bleeding, symptomatic bleeding in a critical organ, or bleeding into a surgical site requiring reoperation, and bleeding leading to hospitalization (includes presentation to an acute care facility without overnight stay). All bleeding that led to presentation at an acute care facility or hospitalization was regarded as major. Recruitment for the COMPASS trial began in February 2013, with an original completion date scheduled for 2018. However, after a mean follow-up period of 23 months and observed superiority of the rivaroxaban and ASA arm, the study ceased in February 2017, a year ahead of schedule. ${ }^{35} \mathrm{~A}$ total of 602 centres across 33 countries were included in the trial. A total of 9,152; 9,117 and 9,126 patients were included in the rivaroxaban + ASA arm, rivaroxaban arm and ASA arm, respectively. The primary outcome occurred in $4.1 \%$ of patients in the rivaroxaban + ASA group, $4.9 \%$ in the rivaroxaban group and 5.4\% in the ASA group (hazard ratio [HR] for rivaroxaban + ASA vs. ASA: 0.76; 95\% confidence interval [CI]: 0.66-0.86; $p<0.001$; HR for rivaroxaban vs. ASA: 0.90; 95\% CI: 0.79-1.03; $p=0.12$ ). The incidence of major bleeding was $3.1 \%$ in the rivaroxaban + ASA group, $2.8 \%$ in the rivaroxaban group and $1.9 \%$ in the ASA group (HR for rivaroxaban + ASAvs. ASA: 1.70; 95\% CI: 1.40-2.05; $p<0.001$; HR for rivaroxaban vs. ASA: 1.51 ; 95\% CI: $1.25-1.84 ; p<0.001)$. The incidence of intracranial bleeding and fatal bleeding was comparable between the rivaroxaban + ASA and ASA groups ( 0.4 vs. $0.3 \% ; p=0.40$ ) and between the rivaroxaban and ASA groups ( 0.5 vs. $0.3 \%$; $p=0.05)$. There were 313 deaths (3.4\%) in the rivaroxaban + ASA group, 366 deaths (4\%) in the rivaroxaban group and 378 deaths (4.1\%) in the ASA group (HR for rivaroxaban + ASA vs. ASA: $0.82 ; 95 \% \mathrm{CI}: 0.71-0.96 ; p=0.01$; HR for rivaroxaban vs. ASA: $0.97 ; 95 \% \mathrm{CI}: 0.84-1.12 ; p=0.67$ ). While significant benefits were observed following use of rivaroxaban $2.5 \mathrm{mg}$ bid + ASA versus ASA alone, the use of rivaroxaban $5 \mathrm{mg}$ bid alone did not lead to a significant reduction in the primary outcome compared with ASA alone and the incidence of major bleeding was again observed to be significantly higher compared with ASA alone. ${ }^{34}$

\section{Vascular Outcomes studY of ASA alonG with Rivaroxaban in Endovascular or Surgical Limb Revascularization for PAD: VOYAGER PAD}

VOYAGER PAD is a phase III, randomized, double-blind, placebo-controlled trial, to determine the efficacy and safety of a dual-pathway treatment approach versus standard care with ASA alone, for the reduction of thrombotic vascular events. ${ }^{36}$ Approximately 6,500 patients with symptomatic and hemodynamic PAD who have undergone technically successful peripheral infrainguinal revascularization within 10 days prior to randomization will be randomized $1: 1$ to receive rivaroxaban $2.5 \mathrm{mg}$ bid plus ASA $100 \mathrm{mg}$ od, or ASA $100 \mathrm{mg}$ od alone. The primary efficacy outcome is the composite of MI, ischemic stroke, CV death, acute limb ischemia (ALI) and major amputation due to PAD. The primary safety endpoint is major bleeding, as assessed by the Thrombolysis in Myocardial Infarction (TIMI) score. ${ }^{36}$ 
VOYAGER PAD began enrolling in late 2015 and results are expected in 2019. VOYAGER PAD complements the COMPASS trial, which is exploring new ways to reduce complications of atherothrombosis in CAD or PAD.

\section{Cardiovascular Outcome Modification, Measurement AND Evaluation of Rivaroxaban in patients with Heart Failure: COMMANDER HF}

COMMANDER HF is an international, phase III, prospective, randomized, double-blind, placebo-controlled, event-driven, parallel-group comparison of the efficacy and safety of rivaroxaban with placebo and standard of care in patients with HF and significant CAD who have experienced a recent exacerbation of $\mathrm{HF}^{28}$ Approximately 5,000 patients will be randomized to receive rivaroxaban $2.5 \mathrm{mg}$ bid plus standard of care versus placebo plus standard of care. Patients will have follow-up visits at week 4 , week 12 , and every 12 weeks for the assessment of outcome events and safety. When it is estimated that 984 primary outcome events have occurred, the investigator sites will be notified of the global treatment end date. It is anticipated that patients will be followed up for 7 to 30 months. The primary efficacy outcome event is a composite of all-cause mortality, MI or stroke. The primary safety outcome is the composite of fatal bleeding or bleeding into a critical space with a potential for permanent disability. ${ }^{28,37}$ COMMANDER HF began enrolling patients in Q3 2013, with results expected in 2019. ${ }^{37}$

Each of these ongoing trials is described in further detail in the accompanying article 'Rivaroxaban: A New Treatment Paradigm in the Setting of Vascular Protection?' by Bauersachs et al.

\section{Stroke Prevention with Rivaroxaban: An Update on Ongoing Trials}

There is a recognized clinical need for effective primary and secondary stroke prevention in several groups. Metaanalysis data have shown that $3.3 \%$ of patients who have undergone transcatheter aortic valve replacement (TAVR) for aortic stenosis (AS) experience a stroke or transient ischemic attack (TIA) within 30 days following TAVR, and patients also have an increased long-term risk of cerebrovascular events due to $\mathrm{AF}^{38}$ There are no clear clinical guidelines recommending any specific antithrombotic regimen for stroke prevention following TAVR..$^{39-41}$

Evidence suggests that 20 to $45 \%$ of patients with AF and CAD require coronary revascularization by $\mathrm{PCI}$ or coronary artery bypass grafting (CABG), ${ }^{42,43}$ and poorer outcomes may be likely in those with both conditions. ${ }^{42-44}$ In patients with AF who have undergone $\mathrm{PCI}$, triple combination therapy with an oral anticoagulant and DAPT is often recommended, ${ }^{45-47}$ despite an associated three- to fourfold increased risk of fatal and nonfatal bleeding. ${ }^{48-52}$

The recorded prevalence of embolic stroke of undetermined source (ESUS; embolic stroke for which the etiology of embolism remains undetermined) varies in the literature due to variations in the definition and degree of investiga- tion, but it is estimated that approximately one in six ischemic strokes is ESUS. ${ }^{53,54}$ Experts propose that diagnosis of ESUS should be based on visualized non-lacunar infarct in the absence of proximal occlusive atherosclerosis or major risk cardioembolic source of embolism. ${ }^{55}$ The risk of recurrent stroke in patients with ESUS has been reported to be as high as $29.0 \%$ over 5 years. ${ }^{56}$ Again, clinical guidelines for the management of ESUS are unclear. A selection of completed and ongoing clinical trials elucidating the role of rivaroxaban in these areas in the rivaroxaban stroke prevention program is covered below.

\section{PIONEER AF-PCI}

PIONEER AF-PCI was an open-label, randomized, controlled, multicenter trial that evaluated the safety of two different regimens of rivaroxaban compared with VKA in patients with NVAF who underwent PCI with stent placement. 23,57 PIONEER AF-PCI included 2,124 stented subjects with NVAF, who were randomized $1: 1: 1$ to treatment with a reduced dose of rivaroxaban at $15 \mathrm{mg}$ od with a $\mathrm{P}_{2} \mathrm{Y}_{12}$ inhibitor for 12 months (Group 1); rivaroxaban $2.5 \mathrm{mg}$ bid with patient stratification to a prespecified duration of DAPT of 1,6 or 12 months (Group 2); or the reference arm of dose-adjusted VKA daily with a similar DAPT stratification (Group 3). The primary safety endpoint was the occurrence of clinically significant bleeding (TIMI major or minor bleeding, or bleeding requiring medical attention) during the 12-month treatment period. Efficacy endpoints were secondary and included the occurrence of major adverse CV events (CV death, MI or stroke). ${ }^{23,57}$

PIONEER AF-PCI completed in late 2016. Findings showed that the rates of clinically significant bleeding were lower in the two groups receiving rivaroxaban than in the group receiving standard therapy (Group 1: 16.8\%; Group 2: $18.0 \%$ and Group 3: 26.7\%; HR for Group 1 vs. Group 3: 0.59; $95 \% \mathrm{CI}$ : 0.47-0.76; $p<0.001$; HR for Group 2 vs. Group 3: $0.63 ; 95 \% \mathrm{CI}$ : $0.50-0.80 ; p<0.001)$. The incidence of major adverse CV events (death from CV causes, MI or stroke) was similar in the three groups (Group 1: 6.5\%; Group 2: 5.6\% and Group 3: $6.0 \%$ ). While the investigational arms had similar efficacy rates, the broad confidence intervals suggest that no solid conclusions can be drawn regarding efficacy. ${ }^{23,57}$ Following completion of PIONEER AF-PCI, the European Medicines Agency (EMA) has since approved the use of rivaroxaban $15 \mathrm{mg}$ od (or $10 \mathrm{mg}$ od for patients with moderate renal impairment [creatinine clearance: $30-49 \mathrm{~mL} / \mathrm{min}$ ]) in combination with a $\mathrm{P}^{2} \mathrm{Y}_{12}$ inhibitor for a maximum of 12 months' duration for the treatment of patients with NVAF who require oral anticoagulation and undergo PCI with stent placement. $^{2}$

\section{New Approach riVaroxaban Inhibition of factor Xa in a Global trial vs Aspirin to prevenT Embolism in Embolic Stroke of Undetermined Source: NAVIGATE ESUS}

NAVIGATE ESUS was a phase III, double-blind, randomized, controlled study to assess the efficacy and safety of 
rivaroxaban versus ASA for the prevention of recurrent stroke and systemic embolism in patients with recent ESUS. ${ }^{58,59}$ Patients were randomized $1: 1$ to rivaroxaban $15 \mathrm{mg}$ od or ASA $100 \mathrm{mg}$ od between 7 days and 6 months after the qualifying ESUS. The primary efficacy outcome was time to recurrent stroke (ischemic, hemorrhagic and undefined stroke, including TIAs with positive neuroimaging) or systemic embolism. The primary safety measure was the first occurrence of a major bleeding event. Between December 2014 and September 2017, a total of 7,214 patients were enrolled from 459 centres across 31 countries. ${ }^{60}$ Mean patient follow-up was expected to be about 2 years, with the trial continuing until at least 450 participants had experienced a primary efficacy outcome eventinitially expected to be February 2018. ${ }^{5,59}$ However, in October 2017, the decision was taken to stop the trial early, based on a recommendation by the Independent Data Monitoring Committee. ${ }^{60}$ Comparable efficacy was noted between the rivaroxaban and ASA arms. Minimal overall benefit was anticipated in the rivaroxaban arm if the study was taken to completion. Overall bleeding rates were low; however, an increase in bleeding was observed in the rivaroxaban arm compared with the low-dose ASA arm. Therefore, the hypothesis that anticoagulation is better than antiplatelet therapy in patients with ESUS could not be confirmed by the NAVIGATE ESUS trial. A complete data analysis is expected in $2018 .^{60}$

\section{Global study comparing a rivAroxaban- based antithrombotic strategy to an antipLatelet-based strategy after transcatheter aortlc vaLve rE-placement to Optimise clinical outcomes: GALILEO}

GALILEO is a phase III, multicentre, open-label, international, randomized, event-driven trial that includes more than 1,520 patients who are without an indication for oral anticoagulation and who have undergone successful TAVR. ${ }^{61,62}$ The trial design includes randomization in a $1: 1$ ratio, at between 1 and 7 days following a successful TAVR, to either a rivaroxaban-based treatment strategy or an antiplateletbased strategy. In the experimental arm, patients will receive rivaroxaban, at a dose of $10 \mathrm{mg}$ od, plus ASA 75 to $100 \mathrm{mg}$ od for 90 days, followed by rivaroxaban alone. In the control arm, patients will receive clopidogrel $75 \mathrm{mg}$ od plus ASA 75 to $100 \mathrm{mg}$ od for 90 days, followed by ASA alone. If new onset $\mathrm{AF}$ (NOAF) develops, the rivaroxaban dose will be raised from 10 to $20 \mathrm{mg}$ od, or from 10 to $15 \mathrm{mg}$ od for subjects with moderate renal impairment (estimated glomerular filtration rate $<50$ and $\geq 30 \mathrm{~mL} / \mathrm{min}$ per $1.73 \mathrm{~m}^{2}$ ). If NOAF occurs within the first 90 days in subjects randomized to the rivaroxaban strategy, ASA will be discontinued at 90 days, and rivaroxaban will be continued as monotherapy. If NOAF occurs under the clopidogrel-based strategy, clopidogrel ( $\leq 90$ days) or ASA monotherapy ( $>90$ days) will be replaced by a VKA to target an international normalized ratio of 2 to 3 . If NOAF occurs within the first 90 days in this group, ASA will be discontinued at 90 days, and VKA continued as a mono- therapy. The primary efficacy endpoint of GALILEO will be the composite of stroke, MI, symptomatic valve thrombosis, PE, DVT, systemic embolism and all-cause death. The primary safety endpoint will be the composite of disabling, lifethreatening and major bleeding events, according to Valve Academic Research Consortium-2 (VARC-2) definitions. ${ }^{61,62}$ Recruitment began in December 2015, from approximately 140 centres across 15 countries, with an anticipated completion date of 2018.

Each of these trials is described in further detail in the accompanying article 'Beyond Stroke Prevention in Atrial Fibrillation: Exploring Further Unmet Needs with Rivaroxaban' by Gibson et al.

\section{Venous Protection with Rivaroxaban: An Update on Ongoing Trials}

There are specific patients with VTE for whom optimal anticoagulant therapy remains challenging. Patients with VTE are known to be at high risk of recurrent thromboembolic events, ${ }^{63}$ which can be further exacerbated by ceasing anticoagulation prematurely owing to potential bleeding risks. Cancer-associated thrombosis (CAT) is also a common cause of morbidity and mortality in patients with malignancy. ${ }^{64-67}$ Recent evidence from the United States suggests that adherence to traditional anticoagulants in the setting of CAT is poor. ${ }^{68}$ Low-molecular-weight heparin (LMWH) continues to be widely recommended for the prevention of CAT in hospitalized patients with cancer and for the treatment of CAT. ${ }^{67,69-71}$ Data supporting the use of NOACs for the prevention and treatment of CAT are lacking, particularly headto-head trials with LMWH. The following trials and programs were designed to investigate rivaroxaban for extended VTE treatment (EINSTEIN CHOICE) and the prevention and treatment of CAT (Cancer Associated thrombosis-expLoring soLutions for patlentS through Treatment and prevention with rivarOxaban [CALLISTO]).

\section{Reduced-Dosed Rivaroxaban in the Extended Prevention of Recurrent Symptomatic Venous Thromboembolism: EINSTEIN CHOICE}

EINSTEIN CHOICE was a phase III, randomized, double-blind trial that compared the safety and efficacy of two doses of rivaroxaban with ASA for the prevention of recurrent VTE. ${ }^{72,73}$ The EINSTEIN CHOICE study assigned 3,396 patients with VTE to receive either rivaroxaban at doses of 10 or $20 \mathrm{mg}$ od or ASA $100 \mathrm{mg}$ od. The patients who were included in the EINSTEIN CHOICE study had previously completed 6 to 12 months of anticoagulation therapy; study drugs were administered for up to 12 months, with a one-month follow-up period. The findings from EINSTEIN CHOICE were that the risk of a recurrent VTE event was significantly reduced with rivaroxaban at a dose of either 20 or $10 \mathrm{mg}$ od than with ASA, without a significant increase in the rate of bleeding. ${ }^{72,73}$

EINSTEIN CHOICE is the only trial to date that has investigated a NOAC in the setting of extended VTE treatment 
Table 1 The CALLISTO program: Summary of ongoing initiatives

\begin{tabular}{|c|c|c|c|c|}
\hline Trial & Design & Dose & Duration & Population \\
\hline \multicolumn{5}{|l|}{ VTE Prevention } \\
\hline CASSINI $^{79}$ & $\begin{array}{l}\text { Prospective, randomized, } \\
\text { double-blind superiority } \\
\text { ( } \sim 700 \text { patients) }\end{array}$ & $\begin{array}{l}\text { Rivaroxaban } 10 \mathrm{mg} \\
\text { od vs. placebo }\end{array}$ & $6 \mathrm{mo}$ & $\begin{array}{l}\text { Ambulatory cancer } \\
\text { patients at high VTE risk } \\
\text { planned to initiate } \\
\text { chemotherapy }\end{array}$ \\
\hline PRO-LAPS $\|^{80}$ & $\begin{array}{l}\text { Randomized, double-blind } \\
\text { ( } \sim 650 \text { patients) }\end{array}$ & $\begin{array}{l}\text { Rivaroxaban } 10 \mathrm{mg} \\
\text { od vs. placebo }\end{array}$ & $\begin{array}{l}\text { Extended } \\
\text { antithrombotic } \\
\text { prophylaxis }\end{array}$ & $\begin{array}{l}\text { Colorectal cancer patients } \\
\text { after laparoscopic surgery }\end{array}$ \\
\hline \multicolumn{5}{|l|}{ VTE Treatment } \\
\hline Select-d ${ }^{81,82}$ & $\begin{array}{l}\text { Randomized, open-label, } \\
\text { multicenter pilot } \\
\text { ( 530 patients) }\end{array}$ & $\begin{array}{l}\text { Rivaroxaban vs. } \\
\text { dalteparina; rivarox- } \\
\text { aban vs. placebo }\end{array}$ & $6 \mathrm{mo}^{\mathrm{b}}$ & $\begin{array}{l}\text { Cancer patients with } \\
\text { symptomatic VTE; PE and } \\
\text { RVT patients }\end{array}$ \\
\hline CASTA-DIVA $^{83}$ & $\begin{array}{l}\text { Randomized, open-label } \\
\text { ( } \sim 200 \text { patients) }\end{array}$ & $\begin{array}{l}\text { Rivaroxaban vs. } \\
\text { dalteparinc }\end{array}$ & $3 \mathrm{mo}$ & $\begin{array}{l}\text { Patients with active cancer } \\
\text { at high risk of VTE } \\
\text { recurrence }\end{array}$ \\
\hline Conko-011 84 & $\begin{array}{l}\text { Prospective, randomized, } \\
\text { open-label, multicenter } \\
\text { ( } \sim 50 \text { patients) }\end{array}$ & $\begin{array}{l}\text { Rivaroxaban vs. } \\
\text { LMWH }^{\mathrm{d}}\end{array}$ & $3 \mathrm{mo}$ & $\begin{array}{l}\text { Patients with active cancer } \\
\text { and newly diagnosed VTE } \\
\text { event }\end{array}$ \\
\hline $\mathrm{QAI}^{85}$ & \multicolumn{4}{|c|}{$\begin{array}{l}\text { Following up CAT patients with VTE whose full anticoagulation course was with rivaroxaban for } 6 \text { mo } \\
\text { (200 patients) }\end{array}$} \\
\hline $\cos \mathrm{MO}^{86}$ & \multicolumn{4}{|c|}{ Patient-reported outcomes, follow-up of 6 mo ( 500 patients) } \\
\hline Frontline- $2^{87}$ & \multicolumn{4}{|c|}{ Second CAT survey of up to 5,000 oncologists/haematologists to identify current practice } \\
\hline
\end{tabular}

Abbreviations: bid, twice daily; CAT, cancer-associated thrombosis; d, days, DVT, deep vein thrombosis; LMWH, low-molecular-weight heparin; mo, month; od, once daily; PE, pulmonary embolism; QAI, Quality Assessment Initiative; RVT, residual vein thrombosis; VTE, venous thromboembolism; wk, week. aDalteparin (200 IU/kg daily subcutaneously for $1 \mathrm{mo}$ and $150 \mathrm{lU} / \mathrm{kg}$ for 2-6 mo); and rivaroxaban (15 mg bid for $21 \mathrm{~d}$ and $20 \mathrm{mg}$ od for $6 \mathrm{mo}$ in total). ${ }^{\mathrm{b}} \mathrm{A}$ second placebo-controlled randomization (rivaroxaban vs. placebo) is comparing the duration of therapy (6 vs. 12 mo) in all patients with PE and those with a DVT who are RVT positive.

'Dalteparin $200 \mathrm{IU} / \mathrm{kg}$ od for $4 \mathrm{wk}$ followed by $150 \mathrm{IU} / \mathrm{kg}$ od for $8 \mathrm{wk}$ or rivaroxaban $15 \mathrm{mg}$ bid for $21 \mathrm{~d}$ followed by $20 \mathrm{mg}$ od for $9 \mathrm{wk}$.

dTherapeutic licensed dose of LMWH according to standards of the individual study centre or rivaroxaban 15 mg bid for $21 \mathrm{~d}$, followed by 20 mg od over a period of 3 mo.

versus ASA, and complements EINSTEIN EXT by further demonstrating the benefit of rivaroxaban at a lower dose of $10 \mathrm{mg}$ od. ${ }^{73}$ Based on EINSTEIN CHOICE results, rivaroxaban $10 \mathrm{mg}$ od is approved for extended prevention of recurrent VTE following $\geq 6$ months of standard anticoagulation, by both the European Medicines Agency and the U.S. Food and Drugs Administration. ${ }^{74,75}$

\section{The CALLISTO Program}

CALLISTO is an umbrella program that addresses multiple clinically relevant questions in CAT via multiple studies, expert recommendations and a survey, the combination of which will result in improved quality of care in oncology. CALLISTO initiatives have been designed in collaboration with oncologists as an overarching international research program to identify and prioritize unmet needs and unanswered questions and to explore the potential role of rivaroxaban in the prevention and treatment of CAT. - Table 1 provides an overview of the CALLISTO initiatives.

EINSTEIN CHOICE and a selection of studies from CALLISTO are described in further detail in the accompanying article 'Treatment Challenges in Venous Thromboembolism: An Appraisal of Rivaroxaban Studies' by Khorana et al.

\section{Conclusion}

Since receiving its first marketing authorization in 2008, rivaroxaban has been approved across several indications for the prevention and treatment of thromboembolic disease. The concept that rivaroxaban impacts not only fibrin formation but also platelet activation forms the basis for new therapeutic approaches in vascular protection. CAT is also an extensive area of investigation within the CALLISTO program. Key findings to date from the new wave of trials in stroke prevention have shown that rivaroxaban is the first NOAC (vs. VKA) to provide data from a dedicated RCTPIONEER AF-PCI-for patients with AF undergoing PCI. The additional benefits of prophylactic dose rivaroxaban $(10 \mathrm{mg}$ od) in extended VTE treatment, as shown in EINSTEIN CHOICE, may mean that physicians can tailor treatments to meet patients' needs and minimize thrombotic risk in the future. A range of hypotheses are currently being tested in new areas of research (see completed and ongoing studies in - Fig. 1). Further studies of note, which are investigating rivaroxaban in under-represented populations, include INVestIgation of rheumatiC aTrial Fibrillation Treatment Using Vitamin K Antagonists, Rivaroxaban or Aspirin Studies, Superiority (INVICTUS-VKA), a program comprising an RCT 
and a registry in rheumatic $\mathrm{AF}$, which is an extension of the Global Rheumatic Heart Disease Registry, REMEDY. ${ }^{76,77}$ The RCT (INVICTUS-VKA) commenced in July 2016 and will ascertain whether rivaroxaban $20 \mathrm{mg}$ od is noninferior to VKAs for the prevention of stroke or systemic embolism, rheumatic $\mathrm{AF}$ and either $\mathrm{CHA}_{2} \mathrm{DS}_{2} \mathrm{VASc} \geq 2$ or moderate to severe mitral stenosis in approximately 4,500 patients. Completion is expected in October 2020. ${ }^{76}$ The RIvaroxaban for Valvular Heart diseasE and atRial Fibrillation Trial (RIVER) is a Phase II, randomized, open-label, noninferiority clinical trial to explore the safety and efficacy of rivaroxaban $20 \mathrm{mg}$ od versus warfarin in patients with persistent or paroxysmal AF or flutter with bioprosthetic mitral valves. ${ }^{78}$ RIVER commenced in August 2015, enrolling approximately 1,000 patients, and is expected to complete in August 2018. ${ }^{78}$ These and other trials from the rivaroxaban clinical development program are addressing major areas of unmet medical needs in thrombosis, and are likely to contribute toward considerable clinical change for practitioners in the future.

\section{Grants or Other Financial Support}

This study received editorial support funded by Bayer AG.

\section{Conflicts of Interest}

A.J.C. has acted in the capacity of advisor and investigator for Bayer, Boehringer Ingelheim, Pfizer/BMS and Daiichi Sankyo.

\section{Acknowledgements}

The author would like to acknowledge Kelly Farrell at Ketchum (Inspired Science), who provided editorial support with funding from Bayer AG.

\section{References}

1 Perzborn E, Roehrig S, Straub A, Kubitza D, Misselwitz F. The discovery and development of rivaroxaban, an oral, direct factor Xa inhibitor. Nat Rev Drug Discov 2011;10(01):61-75

2 Bayer AG. Xarelto Summary of Product Characteristics. Available at: http://www.ema.europa.eu/docs/en_GB/document_library/ EPAR_-_Product_Information/human/000944/WC500057108. pdf. Accessed February 7, 2018

3 Eriksson BI, Borris LC, Friedman RJ, et al; RECORD1 Study Group. Rivaroxaban versus enoxaparin for thromboprophylaxis after hip arthroplasty. N Engl J Med 2008;358(26):2765-2775

4 Kakkar AK, Brenner B, Dahl OE, et al; RECORD2 Investigators. Extended duration rivaroxaban versus short-term enoxaparin for the prevention of venous thromboembolism after total hip arthroplasty: a double-blind, randomised controlled trial. Lancet 2008;372(9632):31-39

5 Lassen MR, Ageno W, Borris LC, et al; RECORD3 Investigators. Rivaroxaban versus enoxaparin for thromboprophylaxis after total knee arthroplasty. N Engl J Med 2008;358(26):2776-2786

6 Turpie AG, Lassen MR, Davidson BL, et al; RECORD4 Investigators. Rivaroxaban versus enoxaparin for thromboprophylaxis after total knee arthroplasty (RECORD4): a randomised trial. Lancet 2009;373(9676):1673-1680

7 Patel MR, Mahaffey KW, Garg J, et al; ROCKET AF Investigators. Rivaroxaban versus warfarin in nonvalvular atrial fibrillation. N Engl J Med 2011;365(10):883-891
8 Bauersachs R, Berkowitz SD, Brenner B, et al; EINSTEIN Investigators. Oral rivaroxaban for symptomatic venous thromboembolism. N Engl J Med 2010;363(26):2499-2510

9 Büller HR, Prins MH, Lensin AW, et al; EINSTEIN-PE Investigators. Oral rivaroxaban for the treatment of symptomatic pulmonary embolism. N Engl J Med 2012;366(14):1287-1297

10 Mega JL, Braunwald E, Wiviott SD, et al; ATLAS ACS 2-TIMI 51 Investigators. Rivaroxaban in patients with a recent acute coronary syndrome. N Engl J Med 2012;366(01):9-19

11 Bayer AG. Bayer Extends Clinical Investigation of Xarelto $₫$ for the Prevention and Treatment of Life-Threatening Blood Clots in Patients with Cancer. Available at: https://www.xarelto.com/en/ resources/newsfeed/bayer-extends-clinical-investigation-of-xarelto-for-the-prevention-and-treatment-of-life-threatening-bloodclots-in-patients-with-cancer/\# Accessed February 7, 2018

12 Angiolillo DJ, Capodanno D, Goto S. Platelet thrombin receptor antagonism and atherothrombosis. Eur Heart J 2010;31(01): $17-28$

13 Cortés-Beringola A, Fitzsimons D, Pelliccia A, Moreno G, MartínAsenjo R, Bueno $\mathrm{H}$. Planning secondary prevention: room for improvement. Eur J Prev Cardiol 2017;24(3 Suppl):22-28

14 Hoffman M, Monroe DM. Coagulation 2006: a modern view of hemostasis. Hematol Oncol Clin North Am 2007;21(01):1-11

15 Coughlin SR. Thrombin signalling and protease-activated receptors. Nature 2000;407(6801):258-264

16 Perzborn E, Heitmeier S, Laux V. Effects of rivaroxaban on platelet activation and platelet-coagulation pathway interaction: in vitro and in vivo studies. J Cardiovasc Pharmacol Ther 2015;20(06): 554-562

17 Mega JL, Braunwald E, Murphy SA, et al. Rivaroxaban in patients stabilized after a ST-segment elevation myocardial infarction: results from the ATLAS ACS-2-TIMI-51 trial (Anti-Xa Therapy to Lower Cardiovascular Events in Addition to Standard Therapy in Subjects with Acute Coronary Syndrome-Thrombolysis In Myocardial Infarction-51). J Am Coll Cardiol 2013;61(18):1853-1859

18 Berger JS, Bhatt DL, Steg PG, et al. Bleeding, mortality, and antiplatelet therapy: results from the Clopidogrel for High Atherothrombotic Risk and Ischemic Stabilization, Management, and Avoidance (CHARISMA) trial. Am Heart J 2011;162(01):98-105. e1

19 Bonaca MP, Creager MA, Olin J, et al. Peripheral revascularization in patients with peripheral artery disease with vorapaxar: insights from the TRA 2 degrees P-TIMI 50 trial. JACC Cardiovasc Interv 2016;9(20):2157-2164

20 Cacoub PP, Bhatt DL, Steg PG, Topol EJ, Creager MA; CHARISMA Investigators. Patients with peripheral arterial disease in the CHARISMA trial. Eur Heart J 2009;30(02):192-201

21 Hur DJ, Kizilgul M, Aung WW, Roussillon KC, Keeley EC. Frequency of coronary artery disease in patients undergoing peripheral artery disease surgery. Am J Cardiol 2012;110(05):736-740

22 Hussein AA, Uno K, Wolski K, et al. Peripheral arterial disease and progression of coronary atherosclerosis. J Am Coll Cardiol 2011; 57(10):1220-1225

23 Gibson CM, Mehran R, Bode C, et al. Prevention of bleeding in patients with atrial fibrillation undergoing PCI. N Engl J Med 2016;375(25):2423-2434

24 Fox KF, Cowie MR, Wood DA, et al. Coronary artery disease as the cause of incident heart failure in the population. Eur Heart J 2001; 22(03):228-236

25 Cugno M, Mari D, Meroni PL, et al. Haemostatic and inflammatory biomarkers in advanced chronic heart failure: role of oral anticoagulants and successful heart transplantation. $\mathrm{Br} \mathrm{J}$ Haematol 2004;126(01):85-92

26 Gibbs CR, Blann AD, Watson RD, Lip GY. Abnormalities of hemorheological, endothelial, and platelet function in patients with chronic heart failure in sinus rhythm: effects of angiotensinconverting enzyme inhibitor and beta-blocker therapy. Circulation 2001;103(13):1746-1751 
27 Watson RD, Gibbs CR, Lip GY. ABC of heart failure. Clinical features and complications. BMJ 2000;320(7229):236-239

28 Zannad F, Greenberg B, Cleland JG, et al. Rationale and design of a randomized, double-blind, event-driven, multicentre study comparing the efficacy and safety of oral rivaroxaban with placebo for reducing the risk of death, myocardial infarction or stroke in subjects with heart failure and significant coronary artery disease following an exacerbation of heart failure: the COMMANDER HF trial. Eur J Heart Fail 2015;17(07):735-742

29 Homma S, Thompson JL, Pullicino PM, et al; WARCEF Investigators. Warfarin and aspirin in patients with heart failure and sinus rhythm. N Engl J Med 2012;366(20):1859-1869

30 Cleland JG, Findlay I, Jafri S, et al. The Warfarin/Aspirin Study in Heart failure (WASH): a randomized trial comparing antithrombotic strategies for patients with heart failure. Am Heart J 2004; 148(01):157-164

31 Cokkinos DV, Haralabopoulos GC, Kostis JB, Toutouzas PK; HELAS Investigators. Efficacy of antithrombotic therapy in chronic heart failure: the HELAS study. Eur J Heart Fail 2006;8(04):428-432

32 COMPASS. ClinicalTrials.gov Identifier: NCT01776424. Available at: https://ClinicalTrials.gov/show/NCT01776424. Accessed February 7, 2018

33 Bosch J, Eikelboom JW, Connolly SJ, et al. Rationale, design and baseline characteristics of participants in the Cardiovascular Outcomes for People Using Anticoagulation Strategies (COMPASS) Trial. Can J Cardiol 2017;33(08):1027-1035

34 Eikelboom JW, Connolly SJ, Bosch J, et al; COMPASS Investigators. Rivaroxaban with or without aspirin in stable cardiovascular disease. N Engl J Med 2017;377(14):1319-1330

35 PR Newswire. Phase 3 COMPASS Study of XARELTO® (rivaroxaban) Stopping Early for Efficacy; Study Meets Primary Endpoint of Prevention of Major Adverse Cardiac Events in Patients with Coronary Artery Disease or Peripheral Artery Disease. Available at: http:// www.prnewswire.com/news-releases/phase-3-compass-study-ofxarelto-rivaroxaban-stopping-early-for-efficacy-study-meets-primaryendpoint-of-prevention-of-major-adverse-cardiac-events-in-patientswith-coronary-artery-disease-or-peripheral-artery-disease-300404477. html. Accessed February 7, 2018

36 VOYAGER PAD. ClinicalTrials.gov Identifier: NCT02504216. Available at: https://ClinicalTrials.gov/show/NCT02504216. Accessed February 7, 2018

37 COMMANDER HF. ClinicalTrials.gov Identifier: NCT01877915. Available at: https://ClinicalTrials.gov/show/NCT01877915. Accessed February 7, 2018

38 Eggebrecht H, Schmermund A, Voigtländer T, Kahlert P, Erbel R, Mehta RH. Risk of stroke after transcatheter aortic valve implantation (TAVI): a meta-analysis of 10,037 published patients. EuroIntervention 2012;8(01):129-138

39 Vahanian A, Alfieri O, Andreotti F, et al; Joint Task Force on the Management of Valvular Heart Disease of the European Society of Cardiology (ESC); European Association for Cardio-Thoracic Surgery (EACTS). Guidelines on the management of valvular heart disease (version 2012). Eur Heart J 2012;33(19):2451-2496

40 Nishimura RA, Otto CM, Bonow RO, et al. 2017 AHA/ACC Focused Update of the 2014 AHA/ACC Guideline for the Management of Patients With Valvular Heart Disease: A Report of the American College of Cardiology/American Heart Association Task Force on Clinical Practice Guidelines. Circulation 2017;135(25):e1159-e1195

41 Nishimura RA, Otto CM, Bonow RO, et al; ACC/AHA Task Force Members. 2014 AHA/ACC Guideline for the management of patients with valvular heart disease: executive summary: a report of the American College of Cardiology/American Heart Association Task Force on Practice Guidelines. Circulation 2014;129(23): 2440-2492

42 Kralev S, Schneider K, Lang S, Süselbeck T, Borggrefe M. Incidence and severity of coronary artery disease in patients with atrial fibrillation undergoing first-time coronary angiography. PLoS One 2011;6(09):e24964
43 Bahit MC, Lopes RD, Wojdyla DM, et al. Apixaban in patients with atrial fibrillation and prior coronary artery disease: insights from the ARISTOTLE trial. Int J Cardiol 2013;170(02):215-220

44 Mehta RH, Dabbous OH, Granger CB, et al; GRACE Investigators. Comparison of outcomes of patients with acute coronary syndromes with and without atrial fibrillation. Am J Cardiol 2003;92 (09):1031-1036

45 January CT, Wann LS, Alpert JS, et al; American College of Cardiology/American Heart Association Task Force on Practice Guidelines. 2014 AHA/ACC/HRS guideline for the management of patients with atrial fibrillation: a report of the American College of Cardiology/American Heart Association Task Force on Practice Guidelines and the Heart Rhythm Society. J Am Coll Cardiol 2014; 64(21):e1-e76

46 You JJ, Singer DE, Howard PA, et al. Antithrombotic therapy for atrial fibrillation: Antithrombotic Therapy and Prevention of Thrombosis, 9th ed: American College of Chest Physicians Evidence-Based Clinical Practice Guidelines. Chest 2012;141(2, Suppl):e531S-e575S

47 Camm AJ, Kirchhof P, Lip GY, et al; European Heart Rhythm Association; European Association for Cardio-Thoracic Surgery. Guidelines for the management of atrial fibrillation: the Task Force for the Management of Atrial Fibrillation of the European Society of Cardiology (ESC). Eur Heart J 2010;31(19):2369-2429

48 Faxon DP, Eikelboom JW, Berger PB, et al. Consensus document: antithrombotic therapy in patients with atrial fibrillation undergoing coronary stenting. A North-American perspective. Thromb Haemost 2011;106(04):572-584

49 Huber K, Airaksinen KJ, Cuisset T, Marín F, Rubboli A, Lip GY. Antithrombotic therapy in patients with atrial fibrillation undergoing coronary stenting: similarities and dissimilarities between North America and Europe. Thromb Haemost 2011;106(04):569-571

50 Lamberts M, Gislason GH, Olesen JB, et al. Oral anticoagulation and antiplatelets in atrial fibrillation patients after myocardial infarction and coronary intervention. J Am Coll Cardiol 2013;62 (11):981-989

51 Lip GY, Huber K, Andreotti F, et al; European Society of Cardiology Working Group on Thrombosis. Management of antithrombotic therapy in atrial fibrillation patients presenting with acute coronary syndrome and/or undergoing percutaneous coronary intervention/ stenting. Thromb Haemost 2010;103(01):13-28. Erratum in Thromb Haemost. 2010 Sep;104(3):653

52 Hansen ML, Sørensen R, Clausen MT, et al. Risk of bleeding with single, dual, or triple therapy with warfarin, aspirin, and clopidogrel in patients with atrial fibrillation. Arch Intern Med 2010;170 (16):1433-1441

53 Hart RG, Catanese L, Perera KS, Ntaios G, Connolly SJ. Embolic stroke of undetermined source: a systematic review and clinical update. Stroke 2017;48(04):867-872

54 Perera KS, Vanassche T, Bosch J, et al; ESUS Global Registry Investigators. Embolic strokes of undetermined source: prevalence and patient features in the ESUS Global Registry. Int J Stroke 2016;11(05):526-533

55 Hart RG, Diener HC, Coutts SB, et al; Cryptogenic Stroke/ESUS International Working Group. Embolic strokes of undetermined source: the case for a new clinical construct. Lancet Neurol 2014; 13(04):429-438

56 Ntaios G, Papavasileiou V, Milionis H, et al. Embolic strokes of undetermined source in the Athens Stroke Registry: an outcome analysis. Stroke 2015;46(08):2087-2093

57 Gibson CM, Mehran R, Bode C, et al. An open-label, randomized, controlled, multicenter study exploring two treatment strategies of rivaroxaban and a dose-adjusted oral vitamin $\mathrm{K}$ antagonist treatment strategy in subjects with atrial fibrillation who undergo percutaneous coronary intervention (PIONEER AF-PCI). Am Heart J 2015;169(04):472-8.e5

58 NAVIGATE-ESUS. ClinicalTrials.gov Identifier: NCT02313909. Available at: https://clinicaltrials.gov/ct2/show/NCT02313909. Accessed February 7, 2018 
59 Hart RG, Sharma M, Mundl H, et al. Rivaroxaban for secondary stroke prevention in patients with embolic strokes of undetermined source: Design of the NAVIGATE ESUS randomized trial. European Stroke Journal 2016;1(03):146-154

60 Bayer AG. Bayer's NAVIGATE ESUS study halted early as it indicated comparable efficacy between treatment arms. Available at: http://press.bayer.com/baynews/baynews.nsf/id/C45F4AFB2CEF BDD0C12581B0004CF01B/\%24File/2017-0301E.pdf?open\&mod $=06.10 .2017 \_08: 49: 26$. Accessed February 7, 2018

61 GALILEO. ClinicalTrials.gov Identifier: NCT02556203. Available at: https://clinicaltrials.gov/ct2/show/NCT02556203. Accessed February 7, 2018

62 Windecker S, Tijssen J, Giustino G, et al. Trial design: Rivaroxaban for the prevention of major cardiovascular events after transcatheter aortic valve replacement: rationale and design of the GALILEO study. Am Heart J 2017;184:81-87

63 Prandoni P, Noventa F, Ghirarduzzi A, et al. The risk of recurrent venous thromboembolism after discontinuing anticoagulation in patients with acute proximal deep vein thrombosis or pulmonary embolism. A prospective cohort study in 1,626 patients. Haematologica 2007;92(02):199-205

64 Stein PD, Beemath A, Meyers FA, Skaf E, Sanchez J, Olson RE. Incidence of venous thromboembolism in patients hospitalized with cancer. Am J Med 2006;119(01):60-68

65 Khorana AA, Francis CW, Culakova E, Kuderer NM, Lyman GH. Thromboembolism is a leading cause of death in cancer patients receiving outpatient chemotherapy. J Thromb Haemost 2007;5 (03):632-634

66 Khorana AA, Francis CW, Culakova E, Kuderer NM, Lyman GH. Frequency, risk factors, and trends for venous thromboembolism among hospitalized cancer patients. Cancer 2007;110(10): 2339-2346

67 Lyman GH, Khorana AA, Kuderer NM, et al; American Society of Clinical Oncology Clinical Practice. Venous thromboembolism prophylaxis and treatment in patients with cancer: American Society of Clinical Oncology clinical practice guideline update. J Clin Oncol 2013;31(17):2189-2204

68 Khorana AA, Yannicelli D, McCrae KR, et al. Evaluation of US prescription patterns: Are treatment guidelines for cancer-associated venous thromboembolism being followed? Thromb Res 2016;145:51-53

69 Mandalà M, Falanga A, Roila F; ESMO Guidelines Working Group. Management of venous thromboembolism (VTE) in cancer patients: ESMO Clinical Practice Guidelines. Ann Oncol 2011;22 (Suppl 6):vi85-vi92

70 Kearon C, Akl EA, Ornelas J, et al. Antithrombotic therapy for VTE disease: CHEST Guideline and Expert Panel Report. Chest 2016; 149(02):315-352

71 Gould MK, Garcia DA, Wren SM, et al. Prevention of VTE in nonorthopedic surgical patients: Antithrombotic Therapy and Prevention of Thrombosis, 9th ed: American College of Chest Physicians Evidence-Based Clinical Practice Guidelines. Chest 2012;141(2, Suppl):e227S-e277S

72 Weitz JI, Bauersachs R, Beyer-Westendorf J, et al; EINSTEIN CHOICE Investigators. Two doses of rivaroxaban versus aspirin for prevention of recurrent venous thromboembolism. Rationale for and design of the EINSTEIN CHOICE study. Thromb Haemost 2015;114(03):645-650

73 Weitz JI, Lensing AWA, Prins MH, et al; EINSTEIN CHOICE Investigators. Rivaroxaban or aspirin for extended treatment of venous thromboembolism. N Engl J Med 2017;376(13):1211-1222

74 Janssen Pharmaceuticals, Inc. FDA Approves New $10 \mathrm{mg}$ Dosing for XARELTO ${ }^{\circledR}$ (rivaroxaban) to Reduce the Continued Risk of Venous Thromboembolism (VTE). Available at: https://www.jnj.com/ media-center/press-releases/fda-approves-new-10-mg-dosing-for-xarelto-rivaroxaban-to-reduce-the-continued-risk-ofvenous-thromboembolism-vte; Accessed February 7, 2018

75 PharmaTimes online. EU OKs low-dose Xarelto to prevent recurrent VTE. Available at: http://www.pharmatimes.com/news/eu_oks _low-dose_xarelto_to_prevent_recurrent_vte_1210333; Accessed February 7, 2018

76 INVICTUS-VKA. ClinicalTrials.gov Identifier: NCT02832544. Available at: https://clinicaltrials.gov/ct2/show/NCT02832544. Accessed February 7, 2018

77 Karthikeyan G, Zühlke L, Engel M, et al. Rationale and design of a Global Rheumatic Heart Disease Registry: the REMEDY study. Am Heart J 2012;163(04):535-40.e1

78 RIVER. ClinicalTrials.gov Identifier: NCT02303795. Available at: https://clinicaltrials.gov/ct2/show/NCT02303795. Accessed February 7, 2018

79 CASSINI. ClinicalTrials.gov Identifier: NCT02555878. Available at: https://ClinicalTrials.gov/show/NCT02555878. Accessed February 7, 2018

80 PRO-LAPS II. ClinicalTrials.gov Identifier: NCT03055026. Available at: https://clinicaltrials.gov/ct2/show/NCT03055026. Accessed February 7, 2018

81 Warwick Clinical Trials Unit. SELECT-D. Anticoagulation Therapy in SELECTeD Cancer Patients at risk of recurrence of venous thromboembolism. Available at: http://www2.warwick.ac.uk/fac/med/ research/hscience/ctu/trials/cancer/select-d/. Accessed February 7, 2018

82 Young A, Phillips J, Hancocks H, et al. OC-11 - Anticoagulation therapy in selected cancer patients at risk of recurrence of venous thromboembolism. Thromb Res 2016;140(Suppl 1):S172-S173

83 CASTA-DIVA. ClinicalTrials.gov Identifier: NCT02746185. Available at: https://clinicaltrials.gov/ct2/show/NCT02746185. Accessed February 7, 2018

84 CONKO-011. ClinicalTrials.gov Identifier: NCT02583191. Available at: https://ClinicalTrials.gov/show/NCT02583191. Accessed February 7, 2018

85 Mantha S, Laube E, Miao Y, et al. Safe and effective use of rivaroxaban for treatment of cancer-associated venous thromboembolic disease: a prospective cohort study. J Thromb Thrombolysis 2017;43(02):166-171

86 COSIMO. ClinicalTrials.gov Identifier: NCT02742623. Available at: https://clinicaltrials.gov/ct2/show/NCT02742623. Accessed February 7, 2018

87 Thrombosis Research Institute. Frontline2. Fundamental Research in Oncology and Thrombosis (FRONTLINE 2) Survey. Available at: http://frontline2.tri-london.ac.uk/. Accessed February 7, 2018 